University of Louisville

ThinkIR: The University of Louisville's Institutional Repository

Electronic Theses and Dissertations

$5-2017$

\title{
A fly has died a splendid death in a pool of strawberry ice cream.
}

Miranda L. Becht

University of Louisville

Follow this and additional works at: https://ir.library.louisville.edu/etd

Part of the Fiber, Textile, and Weaving Arts Commons, Interdisciplinary Arts and Media Commons, and the Sculpture Commons

\section{Recommended Citation}

Becht, Miranda L., "A fly has died a splendid death in a pool of strawberry ice cream." (2017). Electronic Theses and Dissertations. Paper 2677.

https://doi.org/10.18297/etd/2677

This Master's Thesis is brought to you for free and open access by ThinkIR: The University of Louisville's Institutional Repository. It has been accepted for inclusion in Electronic Theses and Dissertations by an authorized administrator of ThinkIR: The University of Louisville's Institutional Repository. This title appears here courtesy of the author, who has retained all other copyrights. For more information, please contact thinkir@louisville.edu. 


\title{
A FLY HAS DIED A SPLENDID DEATH IN A POOL OF STRAWBERRY ICE CREAM
}

\author{
By
}

Miranda L. Becht

B.A., Indiana University Southeast, 2012

B.F.A., Indiana University Southeast 2012

\begin{abstract}
A Thesis
Submitted to the Faculty of

The College of Arts and Science of the University of Louisville in Partial Fulfilment of the Requirements

for the Degree of
\end{abstract}

Master of Fine Arts in Studio Art and Design

Department of Fine Arts

University of Louisville

Louisville, Kentucky

May 2017 



\section{A FLY HAS DIED A SPLENDID DEATH IN A POOL OF STRAWBERRY ICE CREAM}

\section{By}

Miranda L. Becht

B.A., Indiana University Southeast, 2012

B.F.A., Indiana University Southeast 2012

A Thesis Approved on

April 24, 2017

by the following Thesis Committee:

Thesis Director

Scott Massey

Barbara Hanger

Mary Carothers

Rachel Singel

Kevin Gawley 


\section{ABSTRACT \\ A FLY HAS DIED A SPLENDID DEATH IN A POOL OF STRAWBERRY ICE CREAM}

Miranda L. Becht

April 24, 2017

Humans have evolved an overwhelming awareness of self, other, life, and death. We have learned to selectively process information and to replace dissociated memories with less disturbing ones. We have evolved this ability to deceive ourselves, thus producing a personal reality that is innately false.

As a society we tend to idealize our vision of the past, particularly our vision of home. Our idealized notion of home presents itself as a supposedly traditional form of domestic life, but bears little relation to the way people actually lived. This concept of a cozy home full of family love is an invented tradition.

Two poles are created: the ideal and the broken self. The sweetness and pleasure in seeing or recalling certain objects or experiences, that nostalgia, intermingles with feelings of sadness, loss, and regret. Glimmers of memory, perhaps real or perhaps fabricated, become dreamlike flashes in the landscape of our mind. Nostalgia and sentiment can be deconstructed through the frailty and distortion of memory by investigating the reality of lost innocence. 


\section{TABLE OF CONTENTS}

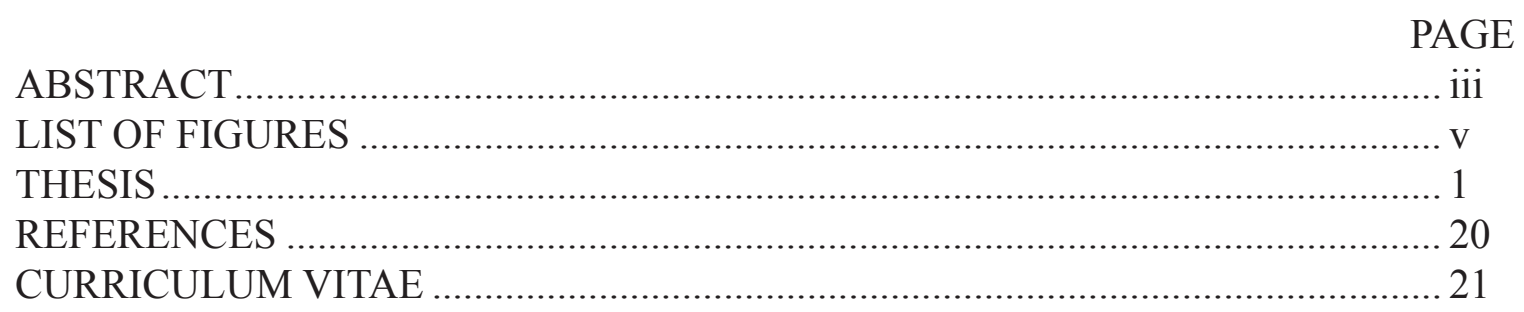




\section{LIST OF FIGURES}

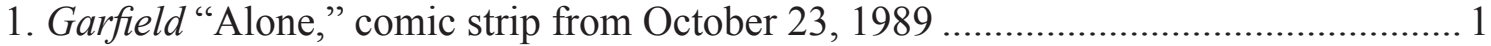

2. Image of text from "The Heat Death of the Universe" by Pamela Zoline....................... 4

3. What's a dream and what is real? (Entropy) by Miranda Becht................................. 6

4. Skin (detail) by Miranda Becht ................................................................................ 10

5. The sweet, nostalgic sadness of something lovely and lost. (Order) by Miranda Becht................................................................................................. 13

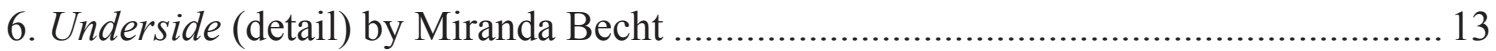

7. Underside by Miranda Becht .................................................................................. 17

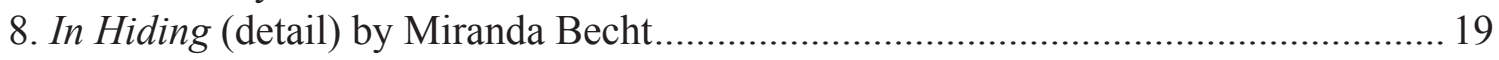



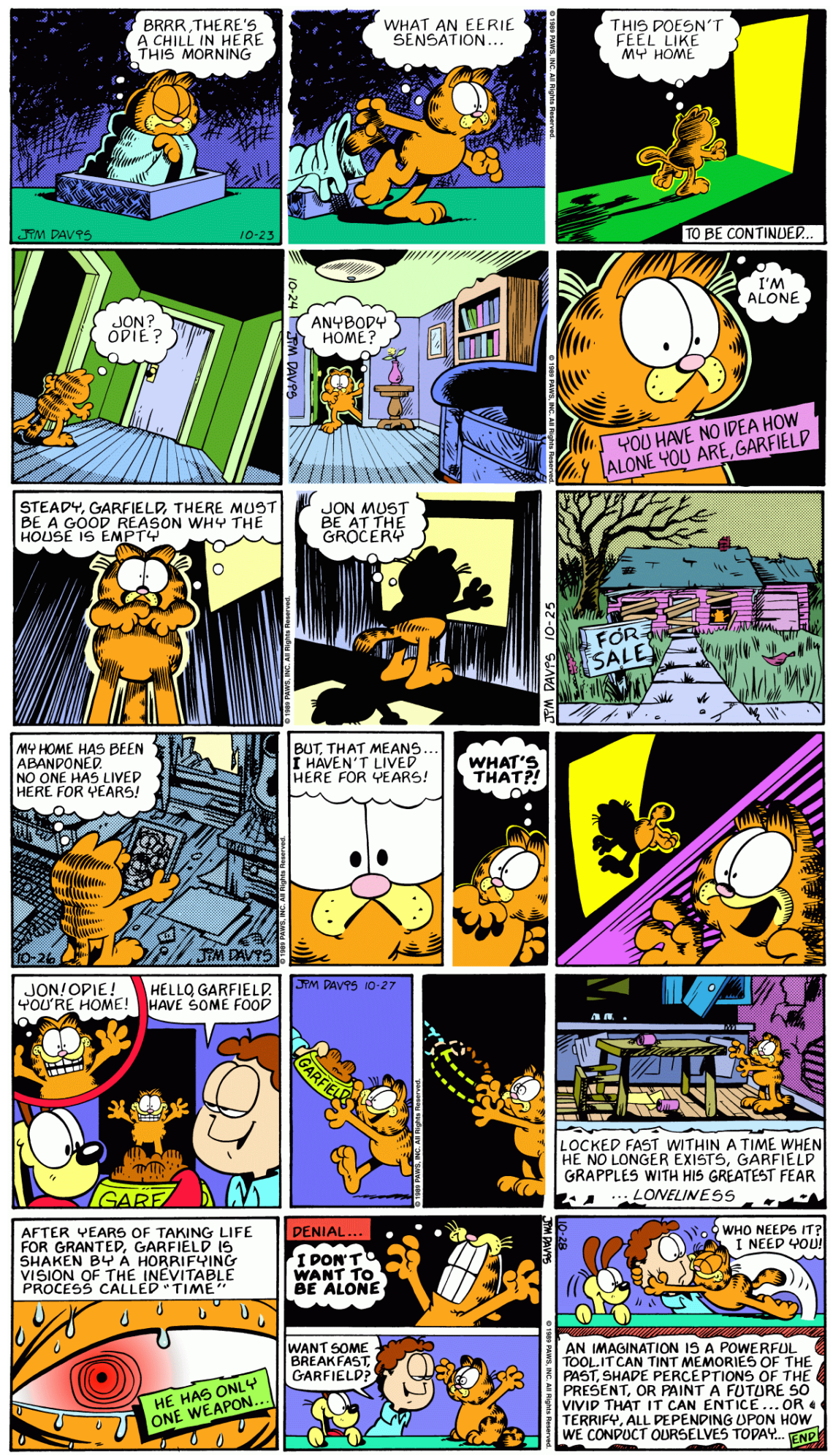

Figure 1. Garfield "Alone," comic strip from October 23, 1989 


\section{"A fly has died a splendid death in a pool of strawberry ice cream."}

"An imagination is a powerful tool. It can tint memories of the past, shade perceptions of the present, or paint a future so vivid that it can entice... or terrify, all depending on how we conduct ourselves today."

-Jim Davis, from Garfield “Alone," October 23, 1989

In “Alone," published in October of 1989, Garfield wakes up in a dilapidated house, alone. There is a fan theory surrounding this comic strip in which Garfield's life to this point has all been imagined. ${ }^{2}$ He has fabricated Jon and Odie as a coping mechanism as he is starving to death. This particular strip was published for Halloween, in some papers under the title "Garfield's Horror Theater." This moniker makes the situation more palatable, however there were several other strips and cartoon specials that share a similar, darker theme. It is quite upsetting to think of my beloved childhood friend, starving to death, alone, and hallucinating his comfortable, lasagna-filled life in order to cope. However, the truth is, our brains do this to us all the time.

\section{If we don't know where we come from, how do we know where we might go?}

Our brains have evolved the ability to make an infinite number of associations to any event. Our memories are comprised of this information, growing throughout our lifetime. Our emotions are entwined with our memories. We have developed innate mechanisms that we use to cope with psychological

1 Pamela Zoline, "The Heat Death of the Universe." Daughters of Earth: Feminist Science Fiction in the Twentieth Century. Ed. Justine Larbalestier. (Middletown, CT: Wesleyan University Press: 2006), 130-143.

2 A quick Google search produces pages of articles, blogs, etc. relating to this fan theory. 
overload. This dissociation is a disintegration. Through dissociation we are able to alter our own reality through a "capacity to enter into different states of consciousness that allow us to maintain separate and contradictory bodies of knowledge"3 and memory. This is vital for us, as "a species whose consciousness demands a constant ordering of reality." "There is a great deal about reality that we simply cannot handle. ${ }^{5}$

Dissociation occurs in both acute and chronic instances. ${ }^{6}$ It is easy to recognize acute dissociation in relation to a specific traumatic event. Chronic dissociation is quiet and slower. It can result from "experiences that we all have every day."7 "Traumatic experience produces a physiological overload that the brain and body are unable to adequately manage..." hyperarousal. Dr. Sandra L. Bloom discusses how “exposure to overwhelming traumatic events and human evolution are intimately entwined" in her paper "Bridging the Black Hole of Trauma: The Evolutionary Significance of the Arts." She quotes author and political activist Barbara Ehrenreich, "The original trauma, meaning of course, not a single event but a longstanding condition- was the trauma of being." Life is dystopian.

"The Heat Death of the Universe" is a domestic science fiction short story by Pamela Zoline. This genre of science fiction deals with domestic or "inner

3 Sandra Bloom, "Bridging the Black Hole of Trauma: The Evolutionary Significance of the Arts," Psychotherapy and Politics International 8, no. 3 (2010): 198-212.

4 Ibid.

5 Ibid.

6 Examples of everyday dissociation can be found in the way many of our behaviors have become automated, such as driving. Driving is potentially a very dangerous activity, yet we regularly "zone out" while performing it.

7 Bloom, “Trauma,” 198-212.

8 Ibid.

9 Ibid. 
space," most often that of women. The domestic category explores interpersonal spaces, but more particularly "those shared by mothers and children, husbands and wives, domestic economy and the public sphere," ${ }^{10}$ or the domain of relationships pertaining to the woman. These stories do so by "extrapolating from the everyday reality of a middle-class American wife and mother a nightmare vision of endless meaningless routine, demands, and expectations, focusing intensely on issues of gender, the ethics of care, and the promise of the future." 11

Readers are first introduced to Sarah Boyle's world with a primer on Ontology. “(1) ONTOLOGY/ That branch of metaphysics which concerns itself with the problems of the nature of existence or being." 12

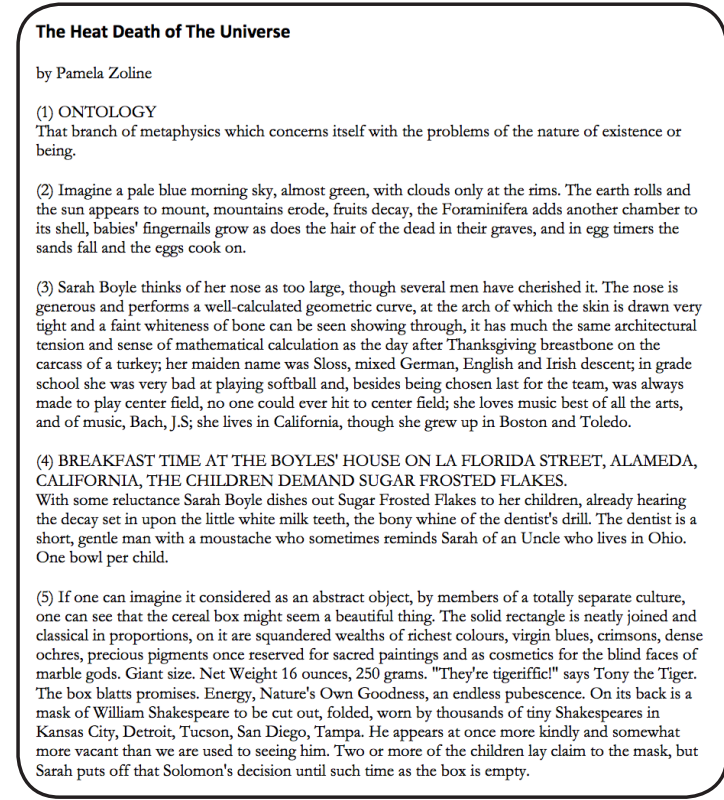

Figure 2. Image of text from "The Heat Death of the Universe" by Pamela Zoline

The story is set up in numbered sections, alternating between descriptions of scientific laws and vignettes of Sarah's life, dealing with themes of birth and continual growth with "babies' fingernails" and death and decay with the "rotting fruit," "the hair of the dead," and the fly who "died a splendid death in a pool of strawberry ice cream." ${ }^{13}$ Sarah lives in a California suburb in a beautiful home with her husband and children. By patriarchical standards, she seems to lead an ideal life. She is, however,

10 Mary Papke, “A Space of Her Own: Pamela Zoline's 'The Heat Death of the Universe'."Daughters of Earth: Feminist Science Fiction in the Twentieth Century. Ed. Justine Larbalestier. (Middletown, CT: Wesleyan University Press: 2006), 145.

11 Ibid.

12 Zoline, "Heat Death," 130.

13 Ibid, 130-143. 
suffering from what Betty Friedan calls the feminine mystique. Friedan states, "There was a strange discrepancy between the reality of our lives as women and the image to which we were trying to conform, the image that I came to call the feminine mystique." 14 Sarah is living in a world where it is thought that women could "find fulfillment only in sexual passivity, male domination, and nurturing maternal love" and the "highest value and the only commitment for women is the fulfillment of their own femininity." 15 Sarah is not happy. She is actually quite numb.

Sarah becomes obsessed with ordering the things in her house, i.e. her world. "Sarah Boyle writes notes to herself all over the house; a mazed wild script larded with arrows, diagrams, pictures, graffiti on every available surface in a desperate/ heroic attempt to index, record, bluff, invoke, order and placate." 16 She makes notes about all sorts of things, including entropy.

On the fluted and flowered white plastic lid of the diaper bin she has written in Blushing Pink Nitetime lipstick a phrase to ward off fumey ammoniac despair. "The nitrogen cycle is the vital round of organic and inorganic exchange on earth. The sweet breath of the Universe." On the wall by the washing machine are Yin and Yang signs, mandalas, and the words, "Many young wives feel trapped. It is a contemporary sociological phenomenon which may be explained in part by a gap between changing living patterns and the accommodation of social services to these patterns." Over the stove she had written "Help, Help, Help, Help, Help."17

\section{A place for everything and everything in its place.}

The best way to stay organized is to keep things in their proper position.

Aside from the obvious places, such as keeping dishes in the kitchen and toiletries in the bathroom, how do we determine where things are kept? I particularly

14 Betty Friedan, The Feminine Mystique (New York: Dell, 1963), 9.

15 Ibid, 43.

16 Zoline, "Heat Death," 132-133.

17 Ibid, 133. 


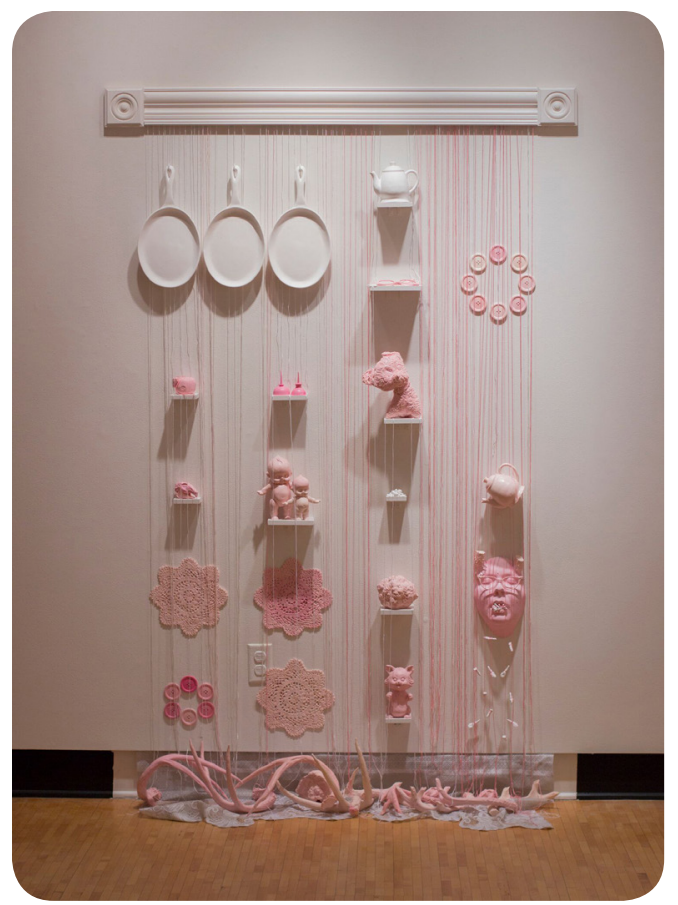

Figure 3. What's a dream and what is real? (Entropy) by Miranda Becht remember the way my grandmother would ritualistically keep, collect, and clean things. My natural tendency to place and display objects is very much rooted in my memories of my grandmother. She kept a plethora of kitsch figurines, tiny oil lamps, memorabilia from Korea, and the like preciously displayed in curio cabinets. I remember sitting in the front living room (that was the one with the nice, barely used furniture, the floral couch, and the green shag carpet). She would tenderly remove an object and tell me the story of how she came to have it and the memories that were attached to it. I was ingrained at a very young age with this attachment to objects and desire to preserve these precious memories.

Just as we desire to collect objects and organize them in a significant way, our brain collects memory and experience. Compartmentalization occurs simultaneously, physically and mentally. The constant demand to impose order on our reality is referred to as "the cognitive imperative." 18 This term speaks to our drive to "order [our] world by differentiation of adaptively significant sensory elements and events, and to the unification of these elements into a systematic, cognitive whole." ${ }^{19}$ Order allows us to create "safety and meaning." ${ }^{20}$ Bloom raises a good question: "How does one place into a meaningful scheme, the idea of one's own death?" or death in general?

18 Bloom, "Trauma," 198-212.

19 Ibid.

20 Ibid. 
Compartmentalization is used as a means to cope with entropy. Entropy is a law of thermodynamics that is discussed by Zoline in "The Heat Death of the Universe."

(13) INSERT ONE. ON ENTROPY.

ENTROPY: A quantity introduced in the first place to facilitate the calculation, and to give clear expressions to the results of thermodynamics. Changes of entropy can be calculated only for a reversible process, and may then be defined as the ratio of the amount of heat taken up to the absolute temperature at which the heat is absorbed. Entropy changes for actual irreversible processes are calculated by postulating equivalent theoretical reversible changes. The entropy of a system is a measure of its degree of disorder. The total entropy of any isolated system can never decrease in any change; it must either increase (irreversible process) or remain constant (reversible process). The total entropy of the Universe therefore is increasing, tending towards a maximum, corresponding to complete disorder of the particles in it (assuming that it may be regarded as an isolated system.) See Heat Death of the Universe. ${ }^{21}$

The brain has evolved "our unique consciousness and its overwhelming awareness of self, other, life, and death." 22 As a result, we developed the “evolutionary strategy that would allow our brain to dissociate itself from its own information when necessary," particularly when contradictions in life become too overwhelming. ${ }^{23}$ The effects of stress wreak havoc on our mind and body. Overwhelming stress is "physiologically and cognitively disorganizing. Dissociation helps to protect and buffer the central nervous system from physiological and emotional hyperarousal." ${ }^{24}$ Dissociation allows us to "deny important aspects of reality that are too disorganizing [and] too threatening to our own inner stability." Our brain keeps this information, though "out of conscious awareness" in case "we should happen to need it." ${ }^{25}$ So, "the memories, feelings,

21 Zoline, “Heat Death," 132.

22 Bloom, "Trauma," 198-212.

23 Ibid.

24 Ibid.

25 Ibid. 
and thoughts associated with dissociated fragments do not disappear from the mind; they simply disappear from consciousness." 26 Those of us who feel compelled, may try to uncover this hidden information through therapy. ${ }^{27}$ We are not ignorant of its presence, though we may not be privy to its exact contents.

The experiences that our brain has deemed worthy of dissociation "could not be categorized, ordered, or placed in a meaning scheme that is in the past and can therefore not be relegated to the past as a memory." 28 These dissociated experiences thus remain "still present." 29 They reestablish themselves as post-traumatic stress symptoms, haunting the person as they reappear as nightmares and flashbacks. ${ }^{30}$ They can manifest as "anxieties, phobias, depression, and a variety of physical symptoms." 31 Melancholia is a "form of mourning" by a person who is unable to properly "grieve the loss of an object, a place, or an ideal," thus becoming haunted by it. ${ }^{32}$ Without the ability to properly order, I am haunted by the same broken melody.

Through our traumatic history as a human race, we have learned to "selectively process information" and to replace dissociated memories with less disturbing memories. ${ }^{33}$ We have evolved the "ability to deceive ourselves," thus producing a personal reality that is innately false. ${ }^{34}$ This raises the question: How much of our existence is fabricated?

26 Ibid.

27 Ibid.

28 Ibid.

29 Ibid.

30 Ibid.

31 Ibid.

32 David Eng, "Melancholia in the Late Twentieth Century,"Signs 25, no. 4 (2000): 1276. 33 Bloom, "Trauma," 198-212.

34 Ibid. 
Our "personal, individual sense of reality is profoundly determined by how much it lines up" ${ }^{35}$ with what our culture defines as reality. What is normative? Our culture defines this idealized notion of what is meant by the word normal. Normal is a social construct. It does not exist. Individuals participate in society. Scholars have theorized that "movement through time and space [is] traumatic." In our society, we "may feel pained by such changes, [we] hesitate to show that emotion lest [we] appear maladjusted." 36 "Those who feel grief" associated with the loss of home "hide the emotion, believing it a sign of immaturity, maladjustment, and weakness." 37 Once an alteration surpasses what is culturally acceptable, twisted forms of reality become psychopathology. Past a certain threshold, a person becomes labeled as "mad" or "delusional."

I grew up surrounded by mental illness. My grandmother and mother both suffered from severe depression, anxiety, bipolar disorder, substance abuse, and at times displayed symptoms of schizophrenia. What I thought was normal as a child is not what I learned to think is normal as an adult. More times than my brain will probably allow me to remember, my mother tried to commit suicide. My uncle once told me that his mother (my grandmother) tried to drive her car off a cliff into a body of water with two of her children in the car. I was raised in verbal abuse. I was raised in unhealthy relationships. I was raised in very altered versions of reality. Our survival is greatly served by the development of "dissociation that allows us to reorder reality in a more palatable way... [and] separate our sense of self from the reality of what is happening." 38

35 Ibid.

36 Susan Matt, "You Can’t Go Home Again: Homesickness and Nostalgia in U.S. History," The Journal of American History 94, no. 2 (2007): 471.

37 Ibid, 497.

38 Bloom, "Trauma," 198-212. 
Traumatic experiences are very disruptive to the way we function. If a person "cannot adequately protect themselves by either fighting or fleeing, then the only option he or she may have open is to separate from- or dissociate- from emotions entirely. This is particularly true for children in frightening situations who are physically unable to fight back or to run away from the source of the danger." 39

I investigate the relationship between control and chaos in a way that is similar to that of Zoline in "Heat Death of the Universe." Just as Sarah Boyle uses compartmentalization to impose order on her life, I very purposely place every item in my installations. I am very conscious of display and its inherent identity politics. By putting my objects on display, I am considering identity and representation. There is a struggle as an other When we are put on display, our agency is removed. As an objectified other, how do we construct our identity?

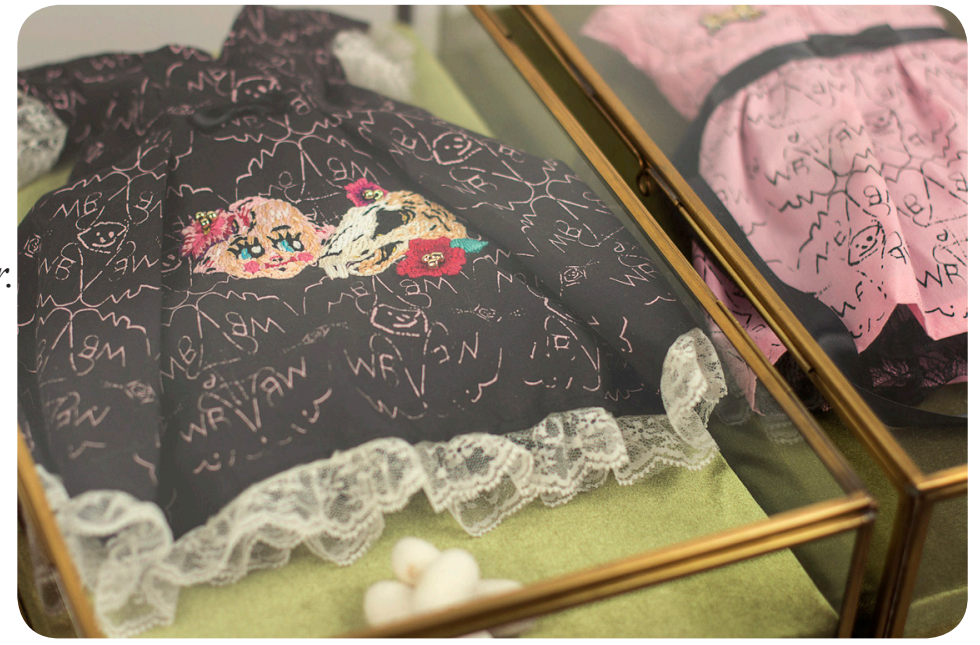

Figure 4. Skin (detail) by Miranda Becht

\section{You Can't Go Home Again}

I have always seemed to long for some sort of metaphorical home, "located somewhere in the past." 40 This "yearning for a lost home" 41 is not a novel phenomenon. It is tied to very common notions of homesickness and nostalgia. The meanings of these two terms have changed over time, but today, "homesickness is defined as the longing for a particular home, nostalgia as a longing for a lost

39 Ibid.

40 Matt, "Home," 469.

41 Ibid. 
time. Nostalgia may carry within it a yearning for home, but it is a home faraway in time rather than space." ${ }^{42}$ Nostalgia, oftentimes used to refer to something sweet and pleasant, is bittersweet. It is the longing for something that is unattainable. Nostalgia represents a person's "attempts to establish continuity with past selves. Longings for lost places, peoples, and times represent a desire to bridge past experience and present conditions." ${ }^{43}$ It is a desire to order and make sense of our reality.

As a society we tend to idealize our vision of the past, particularly our vision of home. Our idealized notion of home presents itself as a "supposedly ancient form of domestic life" and bears "little relation to the way people actually lived in the past." 44 This concept of a cozy home full of family love is an "invented tradition." 45 Historian Susan J. Matt explains that this is a "modern phenomenon that reflects a desire for custom and routine in a world characterized by constant change and innovation." $" 46$

This bittersweet idea of home becomes "a source of comfort and hope." ${ }^{47}$ Collection and display pay "homage to the ideal of the stable home." ${ }^{48}$ It is common practice to preserve "relics of bygone days" 49 and surround ourselves with things that remind us of home. ${ }^{50}$ These treasured objects celebrate "family unity and permanence." ${ }^{51}$ Relics are preserved, collected, and displayed in the

42 Ibid.

43 Ibid, 470-471.

44 Ibid, 479.

45 Ibid.

46 Ibid.

47 Ibid, 481.

48 Ibid.

49 Ibid.

50 Ibid, 497

51 Ibid, 481. 
name of something that is false. They honor "domestic relationships even as they [acknowledge] their fragile nature." 52

Inevitable in our linear understanding of time, we are constantly being "uprooted from home and from the past." ${ }^{53}$ Because of the fallibility of our memory, the past and the home as we remember it, no longer exists, or perhaps it never did. ${ }^{54}$ "The loss of home, the necessity of movement, and the impossibility of return" 55 are painful inevitabilities of life. From this, some may experience "trauma of separation, ${ }^{, 56}$ or at the very least the numb sadness associated with nostalgia. I mourn for a home that perhaps I never had.

I search for kitsch objects and Americana that are charged with nostalgia and sentiment in order to conjure memory narratives in the viewer. Just as a person tends to surround themself with "tokens of home and roots" ${ }^{57}$ which are often "not mementos of their actual homes so much as items associated with the romantic image of home," ${ }^{58}$ the objects that I include in my installations are cast from objects I attain from thrift shops and antique stores. I search for artifacts that "offer a feeling of connection and history, an illusion of timelessness and permanence, even when one is far from home both in time and in place." 59

These objects cause a certain sense familiarity for the viewer. By appropriating these forms I am entering into a dialogue with the past. This conversation plays on the viewer's sense of nostalgia, or perhaps more aptly

52 Ibid, 481.

53 Ibid, 485.

54 Ibid.

55 Ibid.

56 Ibid.

57 Ibid, 497.

58 Ibid.

59 Ibid. 
melancholia, as I intentionally deal with themes of attraction, home, the past, and decay. My nostalgic references to home, "even if they are reproductions," ${ }^{60}$ work on this level to provide some sort of uneasy "comfort and connection to the past." 61

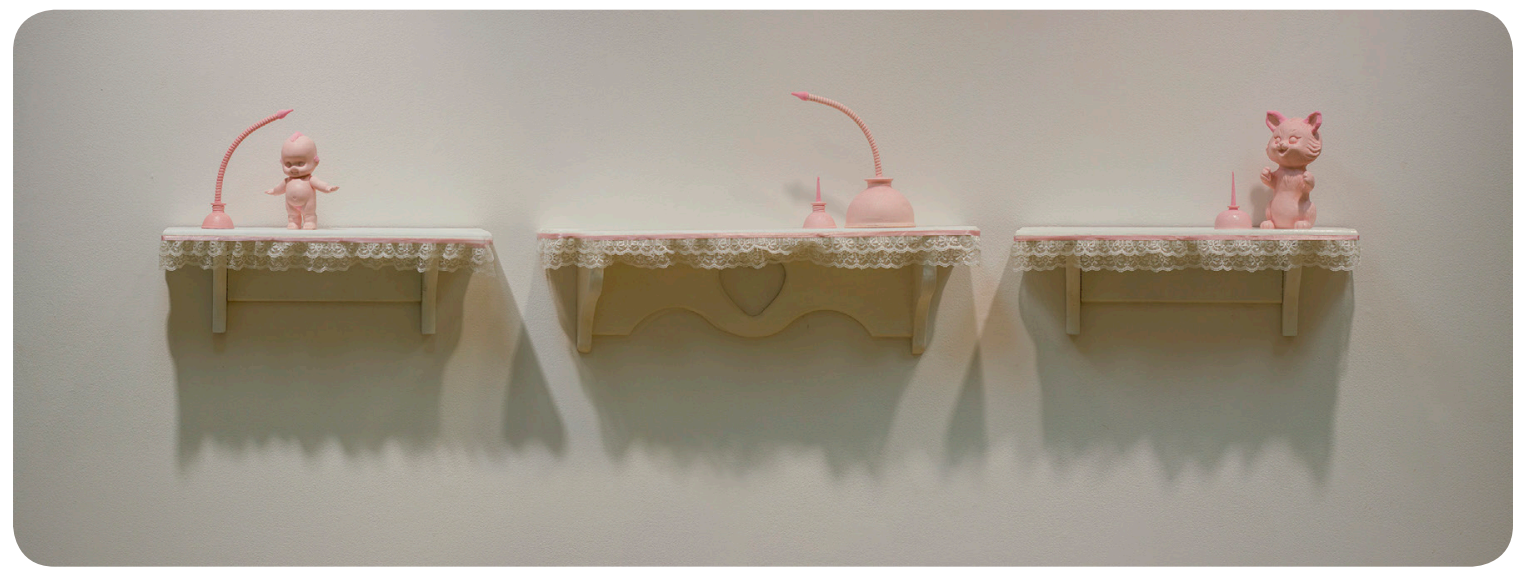

Figure 5. The sweet, nostalgic sadness of something lovely and lost. (Order) by Miranda Becht

The use of kitsch elevates the mundane and references that which is "feminine." These objects are accessible and signify enjoyment. The attractive qualities are also exploitative. These objects work on multiple levels for me. They are cute and innocent, but also serve to reveal how I, as a proxy for all women, girls, and others, have been and are manipulated and exploited. We desire objects/ are objects of desire. The patriarchy demands innocence as it violates it. I also intentionally use the references to home as a domestic, idealized, "safe" place as parallel to women's traditional roles in that space. That, in concert with my pink, kitsch casts reference women's close relationship to commodities and the way we are objectified and gendered from a very young age.

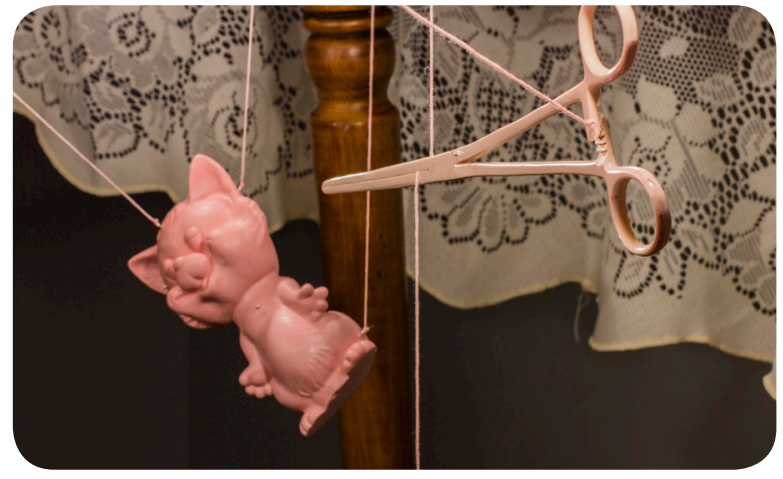

Figure 6. Underside (detail) by Miranda Becht

60 Ibid.

61 Ibid. 
In much of the work, my objects also operate as memory fragments or flashes, referencing the way a certain vision of a past object or place may recur during a post-traumatic stress event. Viewers may form connections between these fragments in the form of memory narratives. The use of the eerily familiar vintage artifact gives substance and authority to this narrative. I enjoy using this cute, kitsch imagery and natural elements that signify decay in concert to create a visual discord. The sweet kitty cats offer comfort while the teeth remind viewers of loss and decay. Both are vessels for an empathetic experience and emotional curiosity.

The repetition of appropriated objects recontextualizes these forms and creates a disruption for the viewer, "[imbuing] them with new meaning." ${ }^{2}$ This act signals that things we thought we knew, we did not know. This calls into question our preconceived notions of truth. Nietzsche said that "truths are illusions about which one has forgotten that this is what they are." ${ }^{63}$ Appropriation creates what Walter Benjamin called "dialectical images," "in which the relationship of past to present is not one of linear time, but of constant negotiation. The past not only influences the present; the present also influences the past... The past is never completed, static, at rest; it too is always vulnerable to reconsideration." ${ }^{64}$

Zoline questions our reality in "Heat Death of the Universe." One way she does so is by positing: what is real in our culture of copies and simulations? What is our state of existence in this post-modern civilization? Order and chaos are different sides of the same coin, just like reality and simulacra. Just as the repetition of copied images in Sarah Boyle's world and in our society creates a simulacrum, so it does in my work. My copies can be treated as though they are

62 Claire Bishop, “Antagonism and Relational Aesthetics." October 110 (2004): 55. 63 Edward Said, "Latent and Manifest Orientalism," Orientalism. (New York: Vintage Books, 1978), 203.

64 Donna Stonecipher, “A Poetics of Appropriation," Hyperallergic (2015). 
the original objects as the hierarchical relationship between the "original" and the "imitation" is deconstructed. We live in an era of replication, where "representation precedes and determines the original." 65 "Real" and "fake" no longer exist, but rather are simulations of reality. We are left with Jean Baudrillard's phenomenon of hyperreality.

Baudrillard theorized about the seductive qualities of the surface of appearances that is created. ${ }^{66}$ We are looking at a "reality that is concealed behind a brilliance of appearances." ${ }^{67}$ We are looking into a dark or denied reality, which lies just beneath the surface. So, we have two spaces that are created, that which is a seductive simulation and that which is the actuality of reality. This is closely tied to the idea of the fetish. ${ }^{68} \mathrm{We}$ are all victims of a comprehensive structure of illusion. We have developed an inability to know and desire to ignore. The dark or denied reality is the reality that you do not know how to see or that you do not want to see. This is where fetishes manifest and dwell.

This tendency to naively believe has created a group false consciousness. Bruno Latour discusses this inclination that has structured our belief system in his essay "Why Has Critique Run out of Steam? From Matters of Fact to Matters of Concern." He states that "facts are made up, that there is no such thing as natural, unmediated, unbiased access to truth." ${ }^{69}$ He goes on to say, "Reality is not defined by matters of fact. Matters of fact are not all that is given in experience. Matters

65 “Simulacra,"(ArtCenter College of Design), people.artcenter.edu/ hyang4/mdp01/ simulacra.pdf.

66 Mark Poster, Jean Baudrillard: Selected Writings (Stanford University Press, 1988), 5. 67 Jacques Ranciere, "The Misadventures of Critical Thought," The Emancipated Spectator (New York: Verso, 2011), 25.

68 Bruno Latour, "Why Has Critique Run out of Steam? From Matters of Fact to Matters of Concern," Critical Inquiry 30 (2004): 225-248.

69 Ibid, 227. 
of fact are only very partial and, I would argue, very polemical, very political renderings or matters of concern." 70

\section{You are not who you see in the mirror.}

As a young child, you see yourself in a mirror. Lacan theorizes that this is when you begin to form a sense of identity. You become conscious of yourself in the mirror and that you are trapped in an environment, in something fundamentally alien to you, outside of you. You differentiate yourself from this otherness. You are shaped by your experience in this environment. A mother raises a baby to see its reflection, placing it in a symbolic universe. The identity assumed depends on the words of the mother, the signifiers; mimicry. All children really know is what their mother tells them. In the mirror, we become unconsciously ingrained with an identification of the ideal. The ideal ego is the image assumed, what you project into the world. The ego that you wear is but a mask, giving you a place, dictating how others see you. This ego seems whole and complete, but it is merely hiding a fragmented, lack of unity. You will never be that ideal. You will never be what you see in the mirror. ${ }^{71}$

Two poles are created, this ideal and the broken self. The sweetness and pleasure in seeing or recalling certain objects or experiences, that nostalgia, intermingles with feelings of sadness, loss, and regret, now residing in an uncanny valley. Glimmers of memory, perhaps real or perhaps fabricated, become dreamlike flashes in the landscape of our mind. Nostalgia and sentiment can be deconstructed through the frailty and distortion of memory by investigating the reality of lost innocence. Childhood is seen as this formative, safe time of innocence and naivety, but how can our mind reconcile wanting to fondly remember while simultaneously

70 Ibid, 232.

71 Lionel Bailly, Lacan: A Beginner's Guide (London: Oneworld, 2009), 28-40. 
recalling, say, childhood trauma or suffering? How can I reconcile this dialectic?

This notion of "polar ideas" or "system of oppositions" occurring in the process and theoretical approaches surrounding it is undeniably related to the philosophy of dialectics, wherein a discourse occurs between two opposing views, which can be regarded as two ends on the same bridge. ${ }^{72}$ Two seemingly disparate ideas at once are in opposition and accord. These pairs rely on one another. If we did not know noise, we could not know silence.

I am very concerned with exploring the relationship of dialectics. Lacan's mirror stage creates a dialectic between the ego and the reality of the fragmented self. Similarly, Latour discusses the relationship between the "brilliance of appearances" and the dark or denied reality. I have recently been investigating these relationships in the way I approach space in my work, particularly domestic

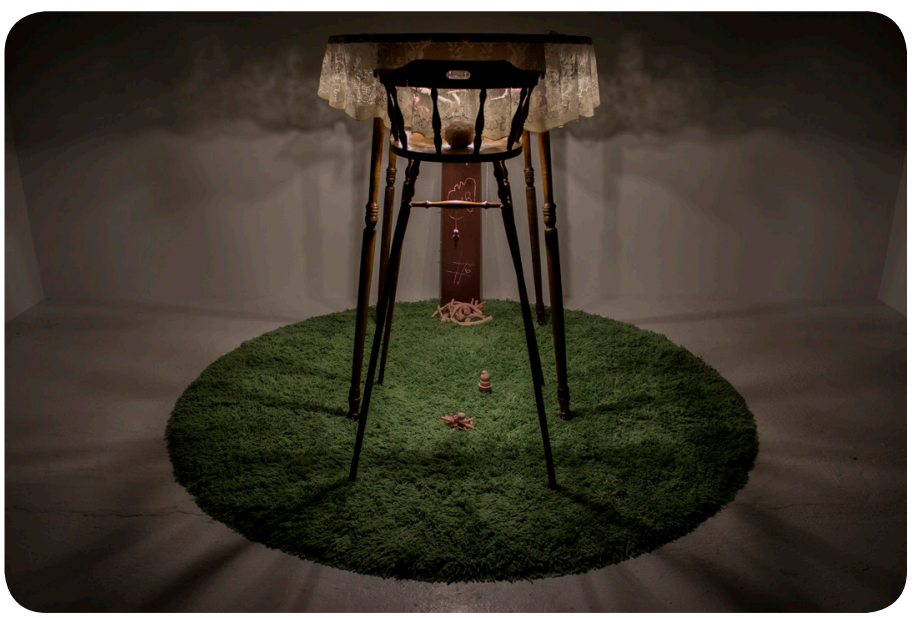

Figure 7. Underside by Miranda Becht spaces. In "Underside" I use the familiar form of a dining room table. The tops of the tables in our homes get all of our attention. My grandmother and mother took great pains to make sure the tabletops had a perfect appearance, adorning them with nice tablecloths, fine china, and shiny decorations. I particularly remember the ritualistic way my grandmother would add the leaves (which were always kept leaning against the adjacent wall) and neatly set the dining room table before a dinner. The women in my family went to great lengths to "keep up appearances"

72 Hans Ulrich Obrist. "Do It," Ways of Curating (New York: Faber and Faber, 2016), 129. 
and make sure they projected a very beautiful, put-together impression to others, even though it was just a façade.

I was always more interested in the bottom of the table and could often be found playing under it. It provided an adequate haven to me if all the chairs were pushed in. All of the tables in the house had small drawings underneath that were my little secrets. There was something so special about having that space and having the small act of mischievous defiance. I am an only child and underneath the dining room table was a clubhouse just for me. In this work I am investigating the relationship between top and bottom, ego and fragmented self, and appearances versus reality.

Thinking about these particular experiences and remembering the reality of my life (my mother's life, my grandmother's life), makes me wish that I could just be nostalgic for childhood innocence. However, I cannot separate from the disruptions I experienced. That is my reality. I long to romanticize the past, and there is a part of me that does, but stopping there denies my biography. I feel I am trapped in this borderland between nostalgia and melancholia. My work is mediating this bridge and unifying these two spaces. To quote Hans Ulrich Obrist, life is a "continuously articulated struggle between the past, the present, and the future... [the] vision of history [is] under constant negotiation." ${ }^{73}$ By recontextualizing and remembering, I am creating a new space and temporality.

I am also investigating the dialectic between old and new in my process of casting. As discussed, I curate objects for my installations from hunts in thrift shops, flea markets, and antique stores. I choose objects that excite and enter into discourse with me. I make silicone molds of these vintage objects and cast them anew, most frequently out of pink tinted resin. Resin is a synthetic, plastic-y

73 Ibid. 
material. This is a very deliberate recontextualization. Not only does it reference simulacra and appropriation, but it is a direct reference to the way our memory, behaving much like an echo, changes over time. Creating this very real, visceral object out of a fake, plastic material adds a conceptual layer alluding to the way our memories and desires become fake and manufactured over time.

\section{The pleasant, nostalgic sadness of something lovely and lost.}

I have fond memories. I

remember green shag carpet. I love that carpet. I dream about that carpet. I often sat on that carpet as a child, running my fingers through it. I loved the avocado color, the soft strands squeezed between my fingers, the smell. I would get really close, press my cheek against the floor. I loved the fine fuzzy wisps that stuck out of the small crevices created by the spun fibers. That green carpet was comfortable. That green carpet was home.

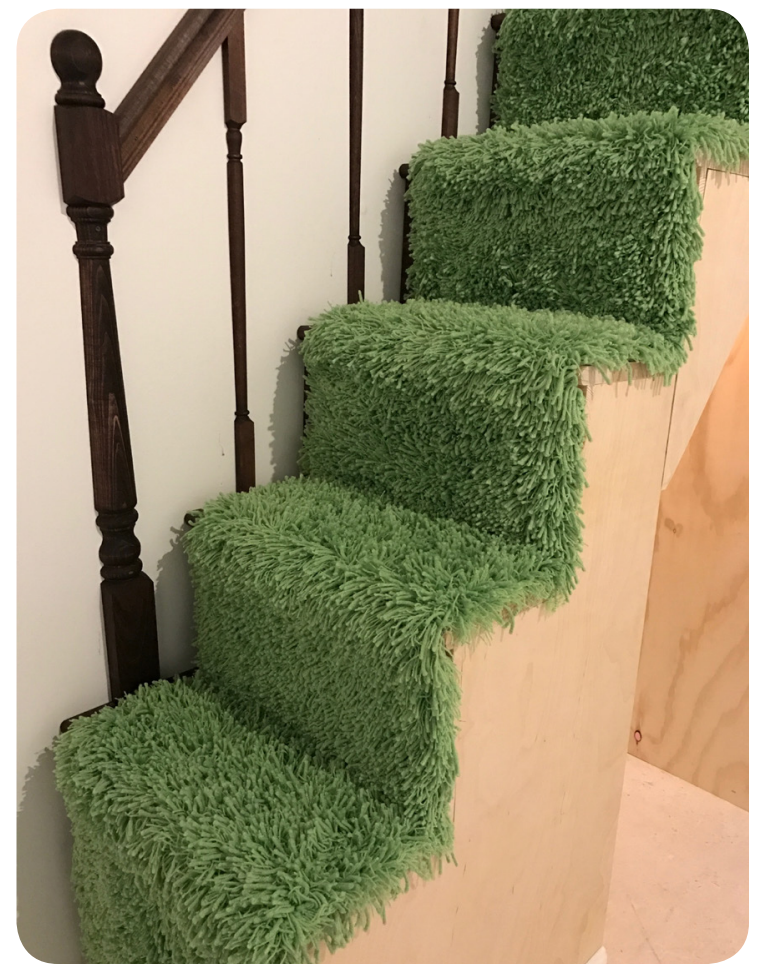

Figure 8. In Hiding (detail) by Miranda Becht

I would sit and play with an odd, white vessel, full of wonder about its use and its origin. This vessel seemed so big, so white and pure, so curious. My grandmother told me it was a bedpan, but it wasn't until much later in life that I realized just what a bedpan was. My most cherished childhood memory is soiled with urine and feces.

Lost innocence often takes the guise of idealized memories. My work is a vehicle for my fetishized, fragile memories. I am pressured to be the object of desire... this untrue illusion, the ideal. 


\section{REFERENCES}

Bailly, Lionel. Lacan: A Beginner's Guide. London: Oneworld, 2009.

Bishop, Claire. “Antagonism and Relational Aesthetics.” October (110, Fall 2004), 55.

Bloom, Sandra. "Bridging the Black Hole of Trauma: The Evolutionary Significance of the Arts." Psychotherapy and Politics International 8, no. 3 (2010): 198-212.

Eng, David. “Melancholia in the Late Twentieth Century.” Signs 25, no. 4 (2000): 1275-1281.

Friedan, Betty. The Feminine Mystique. New York: Dell, 1963.

Latour, Bruno. "Why Has Critique Run out of Steam? From Matters of Fact to Matters of Concern.” Critical Inquiry 30 (2004): 225-248.

Matt, Susan. "You Can't Go Home Again: Homesickness and Nostalgia in U.S. History." The Journal of American History 94, no. 2 (2007): 469-497.

Obrist, Hans Ulrich. "Do It.” Ways of Curating. New York: Faber and Faber, 2016.

Papke, Mary E. “A Space of Her Own: Pamela Zoline's 'The Heat Death of the Universe'." Daughters of Earth: Feminist Science Fiction in the Twentieth Century. Ed. Justine Larbalestier. Middletown, CT: Wesleyan University Press: 2006. 144-159.

Poster, Mark. Jean Baudrillard: Selected Writings. Stanford University Press, 1988.

Ranciere, Jacques. "The Misadventures of Critical Thought," The Emancipated Spectator. New York: Verso, 2011.

Said, Edward W. "Latent and Manifest Orientalism." Orientalism. New York: Vintage Books, 1978.

Stonecipher, Donna. “A Poetics of Appropriation.” Hyperallergic, 2015.

Zoline, Pamela. "The Heat Death of the Universe." Daughters of Earth: Feminist Science Fiction in the Twentieth Century. Ed. Justine Larbalestier. Middletown, CT: Wesleyan University Press: 2006. 130-143. 


\section{CURRICULUM VITAE}

Miranda Becht

414 E. Spring St. • New Albany, IN 47150 •(812) 207-7664•mirandabecht@gmail.com

\section{Education}

$\begin{array}{llll}\text { MFA } & 2017 & \text { Sculpture } & \text { University of Louisville } \\ \text { BFA } & 2012 & \text { Ceramics } & \text { Indiana University Southeast } \\ \text { BA } & 2012 & \text { Printmaking } & \text { Indiana University Southeast } \\ \text { Minor } & \text { Psychology } & \end{array}$

\section{Selected Professional Experience}

2015-2017

2016

2016

2015-2016

2014-2015
Graduate Teaching Assistant, University of Louisville, created curriculum and taught foundations courses in two-dimensional design, three-dimensional design, and introduction to art history; assisted in introductory drawing courses

\#IAMPUBLICART Event, Carnegie Center for Art and History and University of Louisville, planned and implemented large scale public art work

Jeffersonville Public Art Commission, assisted in fabrication of puppets for The Stunning Bicentennial Puppet Extravaganza: Pioneering Spirits of Clark County

Aegis member, University of Louisville, published exhibition reviews on group blog, co-curated exhibition Larry and Ladonna was here that was held at KMAC

Graduate Research Assistant and printmaking studio assistant, University of Louisville, assisted in introductory printmaking courses, tended to printmaking studio maintenance

Commissioned to create public art through the Jeffersonville Public Art Committee, Creative Crosswalks, Curated by JPAC, Jeffersonville, IN,

Commissioned to create public art through the Jeffersonville Public Art Committee, Powering Creativity, Jeffersonville, IN 
2011-2014

2012,2013

2012

2012

2010-2011

2009

2009

2008-2009

2007
Assistant Manager/ Tour Manager, Payton Glass Center (formerly Glassworks), Louisville, KY, fused glass workshop instructor, tour guide, production artist

Volunteer for The New Albany Public Art Project Bicentennial Series, through the Carnegie Center for Art and History, ran a screen printing booth, helped the public with poster project, New Albany, IN

Ceramics teacher, summer camp teacher, and assistant at Spot Five Studios, Louisville, KY, created curriculum and taught various art courses

Teaching assistant, Arts Institute, Young Artists Workshops, Indiana University Southeast

IUS Fine Art Program work-study dealing with gallery preparation and assisting professor with various tasks, such as paperwork, class preparation, and studio maintenance, Indiana University Southeast

Completed 15 hours of practicum work with grades K-5 in art classes under Cathy Gruninger at Bridgepoint Elementary School, Jeffersonville, IN

Completed 15 hours of practicum work with grades 9-12 in studio art and art history classes at Louisville Male High School under Judy Fertig, Louisville, KY

Teaching assistant, Jeffersonville High School Art Club, Jeffersonville, IN

Completed 8 hour job shadow under Cathy Gruninger at Bridgepoint Elementary School, working with grades K-5 in art class, Jeffersonville, IN

\section{Technical Abilities}

Monotype three color separation print process; screen printing; plaster mold making; slip casting; silicone mold making; resin casting; electric kiln firing; Raku firing; gas kiln firing; throwing on a potter's wheel; handbuilding clay construction; operation of power tools including handheld and press drills, miter saw, table saw, vertical table saw, band saw, jig saw, handheld and belt sanders, lathe, pneumatic nail gun, sewing machine, Dremel tool; beginning MIG welding; soldering; Mac and PC proficient 
Selected Honors

2017

2016-2017

2012

2011

2010

2007-2012

2004-2012
Outstanding Graduate in Fine Arts Award from Hite Art Institute

Nora Iasigi Bullitt Memorial Outstanding Work in Sculpture Award Graduated with Honors Distinction

Art History Award, IUS Juried Student Art Exhibition 2011

Preston's Ceramic Best in Show Award, IUS Juried Student Art Exhibition

People's Choice Award, IUS Library Art Exhibition 2011

Recipient of Kate Torp Memorial art scholarship

Printmaking best overall award, IUS Juried Student Art Exhibition 2010

Susan and Kyle Rideout Purchase Award, IUS Juried Student Art Exhibition

Printmaking concentration award of merit, IUS Library Art Exhibition 2010

Chancellor's Honors List

Dean's List

\section{Shows and Exhibitions}

2017 MFA Thesis Exhibition: The fly has died a splendid death in a pool of strawberry ice cream. Cressman Center for Visual Arts, Louisville, KY

2016 Mantra: It Bears Repeating, Barr Gallery, Indiana University Southeast \#IAMPUBLICART, Carnegie Center for Art and History, New Albany, IN MFA Colloquium, Dario Covi Gallery, University of Louisville

2015 Fire and Art 9: MFA Showcase, Cressman Center for Visual Arts, Louisville, KY

2014 Untitled, Mellwood Arts and Entertainment Center, Louisville, KY

Curator: Meg Loop, Curatorial Assistant at Tim Faulkner Gallery and

Curator at Mellwood Arts \& Entertainment Center

Artifactual: Kitties, and Owls, and Kitsch! Oh My! (Solo Exhibition), Silica Ceramic

Studio, Jeffersonville, IN

Creative Crosswalks, public art Commission, Jeffersonville, IN

Curators: JPAC

2013 Powering Creativity, public art commission, Jeffersonville, IN

2012 The Block Show, Spot5 Studios, Louisville, KY

Rites of Passage, Manifest Gallery, Cincinnati, $\mathrm{OH}$

Curator: Jason Franz, Executive Director, Chief Curator, Visual Artist and

Adjunct Assistant Professor, University of Cincinnati

Femme Fatale, BFA Thesis Exhibition, Barr Gallery, Indiana University Southeast Introducing, Graduating BA Exhibition, Barr Gallery, Indiana University Southeast IUS Fine Art Open House, sponsored by the Dirt Bags Art Club, Indiana University Southeast 
2011 Clean Fossils, Fine Art Exhibition, New Albany, IN

IUS Juried Student Art Exhibition 2011, Barr Gallery, Indiana University Southeast, Juror: Joey Yates, Curator for LOT Gallery, Louisville, KY

Nostalgia, joint art exhibition, Indiana University Southeast Spacelab Gallery

IUS Library Student Art Exhibition 2011, Indiana University Southeast Library

Gallery; Juried by IU Southeast librarians

IUS Fine Art Open House, sponsored by the Dirt Bags Art Club, Indiana

University Southeast

The Illest Show the Spacelab Has Ever Seen, Indiana University Southeast

Spacelab Gallery

Curator: Ashley Stewart, ceramic artist, Jeffersonville, IN

2010 IUS Juried Student Art Exhibition 2010, Barr Gallery, Indiana University

Southeast, Juror: Daniel Graham, Professor of Art at Georgetown College

The Reject Show, Indiana University Southeast Spacelab Gallery

IUS Fine Art Open House, sponsored by the Dirt Bags Art Club, Indiana

University Southeast

IUS Library Student Art Exhibition 2010, Indiana University Southeast Library

Gallery; Juried by IU Southeast librarians

IU Southeast Celebrates Dia De Los Muertos: A Celebration of our Cultures, Barr

Gallery, Indiana University Southeast

Curator: Pako Martin, designer, New Albany, IN/ Mexico

2009 IUS Juried Student Art Exhibition 2009, Barr Gallery, Indiana University

Southeast, Juror: Julie Schweitzer, Executive Director of the Arts Council

of Southern Indiana

IUS Fine Art Open House, sponsored by the Dirt Bags Art Club, Indiana

University Southeast

Junk Food Collaborative Portfolio, Indiana University Southeast Library and

Aronoff Center for Design and Art, University of Cincinnati, $\mathrm{OH}$

2008 IUS Juried Student Art Exhibition 2008, Barr Gallery, Indiana University

Southeast, Juror: Scott Scarboro, Practicing Artist, Louisville, KY 